\title{
Research and Design of Regional Education Cloud System Based on University
}

\author{
Ping Xia ${ }^{1, a^{*}}$, Liang Zhang ${ }^{1, b}$ and Zhifeng Zeng ${ }^{1, c}$ \\ ${ }^{1}$ Guangzhou College of Technology and Business, China. \\ a710398795@qq.com, b272130403@qq.com, c513994133@qq.com
}

\begin{abstract}
Keywords: Cloud computing; Big data; Education informatization; Resource sharing; Regional education cloud
\end{abstract}

\begin{abstract}
With the development of cloud computing, big data, mobile interconnection, Internet of Things technology and the construction of educational information, the degree of resource sharing among various colleges and universities is low, and the phenomenon of information islands is serious, which can not meet the development needs of education informatization, and it is urgent to reform and innovate[1]. The article analyzes the principles and goals of the regional sharing education cloud, and designs the basic framework and functional modules of the regional education cloud, which will provide reference for the sharing of regional college resources and the popularization of educational information.
\end{abstract}

\section{Development of Resource Sharing in Universities}

In the information platform construction of various universities, due to the difference in investment, technology used, design framework, and scale of development, the following three problems have arisen in the sharing of educational resources in colleges and universities: the phenomenon of "information isolated islands" in universities has become increasingly seriously; the level of resource sharing among colleges and universities is low, and there is a phenomenon of "strength and weakness"; the lack of resource integration platform makes it difficult to achieve a unified pool of resources[2].

The phenomenon of "information isolated islands" in universities is becoming increasingly serious. Due to the informatization construction of major universities, they independently design and develop their own resource management systems. They lack standardized, uniform, and compatible technical specifications and cannot build an integrated educational resource community, making it difficult to share information resources in colleges and universities, and the phenomenon of "information isolated islands" in education has become increasingly prominent. In addition, the educational information resources in various universities are relatively fragmented, lack of unified design and planning, and the school's own application system is low in integration and resource management is difficult. What is more serious is the problem of repeated construction, repeated investment, waste of resources, and low efficiency in the process of informationization in various universities, which is not conducive to the construction and development of education informatization.

The degree of resource sharing in colleges and universities is low, and there is a phenomenon of "strength and weakness". Universities in the construction of the Internet and the application of information, there is a general situation of "longitudinal strong and transverse weak". "Longitudinal strong" refers to the network system in the vertical departments of universities and colleges is relatively strong and can meet the application services of the university. "Transverse weak" refers to the problem of partial information isolation in the horizontal interconnection and intercommunication among colleges and universities, the degree of information sharing is relatively low[3]. Due to the open nature of the network environment and the decentralized geographical location of universities, although universities and colleges have invested heavily in the construction of educational resources of the university and have abundant resources, but they can only achieve the sharing of resources within the university. In addition, due to the distributed network 
environment, the limitations of professional technology, and the incompatibility of various university resource platforms, it is difficult to achieve information transfer and sharing among universities.

Lack of resource integration platform makes it difficult to achieve uniform pooling of resources. At present, colleges and universities are relatively decentralized and independent in the management of their education and teaching resources. Due to the lack of a unified platform for resource integration, they have severely constrained the development of the demand for resource sharing among colleges and universities, and the emergence of educational resources in the region is difficult to converge, difficult to achieve and difficult to share. Only after the establishment of a standardized, safe and efficient resource integration platform can we fundamentally solve the problem of resource sharing in universities and provide a basic big data platform for resource sharing in colleges and universities[4].

\section{Principles and Achievements of Regional Education Cloud}

According to the strategic deployment of the "Thirteenth Five-Year Plan for Educational Information" released by the Ministry of Education in 2016, the development goals for the education sector in the next decade in China are determined. That is, the use of high technology such as cloud services, big data, mobile interconnection, and internet of things is highly integrated with the education field to form a new education model, and a nationwide interconnection-based education resource sharing system based on cloud services is established to comprehensively promote education informatization. In order to gradually realize the sharing of educational resources across the country, first, on the basis of provinces and cities as a unit, a regional education cloud platform based on resource sharing in universities is constructed so as to continue to cover a larger area.

The regional education cloud can be understood as providing the necessary hardware and software resources for education informatization through cloud computing within a certain geographic scope. After these resources are collected and virtualized, various cloud services are provided, which is a modern education informatization construction[5]. The design principle of the regional education cloud is based on cloud computing and big data technology, it establishes a unified education cloud platform in the province-unit colleges and universities, uses super large data pools to store high-quality educational resources, and provides various application service platform and expansion of application platform to realize the sharing of education and teaching resources among universities. The construction of a regional education cloud platform is an important measure to promote education informatization[6]. It will also provide a competent education cloud service platform for educational authorities, universities, teachers, and students. Through the regional education cloud, it mainly achieves the following goals:

Unified convergence, integration, distribution and management of various types of quality education resources, and balanced distribution of educational resources, forming a complete, open and secure educational resource information database and public service platform based on big data.

Provide one-stop online learning, experience sharing, and mutual assistance and cooperation among universities, teachers, and students. College administrators can through the space of education, better manage school affairs, and can also learn from other universities' excellent management experience to better serve the school; teachers can learn advanced teaching experience, enhance scientific research capabilities, and achieve cross-school collaboration and cooperation; students can share learning experience, make friends widely, and better enrich learning and life[7].

Through the unified planning, deployment, management and maintenance of regional education cloud service platform. Reduce redundant construction in universities, reduce investment in manpower and financial resources, and reduce the cost of comprehensive information construction.

\section{System Architecture Design of Regional Education Cloud}

The design idea of the regional education cloud system is that the government education department 
conducts unified deployment management, implements a secondary management system based on the "education department + universities" , and provides management, teaching, and learning to three types of user groups: universities, teachers, and students, the educational cloud service meets the needs of educational activities as much as possible. The system is designed and planned uniformly by the regional government and the education authority, and the task distribution mechanism is needed. It calls for the joint cooperation of colleges and universities, and encourages the social education institutions to participate in the construction of the platform. The main frame design is shown in Fig. 1.

The system architecture of the regional education cloud platform is mainly composed of three parts: the cloud service center, management layer, and user layer. Among them, the cloud service center is located at the core of the region, and provides education resource sharing services of " $3+5+\mathrm{N}$ ", namely, three types of user groups: universities, teachers, and students in the region; providing three resource data pools, five basics education and teaching applications and $\mathrm{N}+$ expansion application services to achieve regional sharing of educational resources.

On the educational cloud platform, the cloud service center is a large-scale data warehouse where education resources are stored. It needs to be equipped with high-performance server farms, large databases, and various hardware and software integration resources to provide digital resource sharing service based on the C/S model for all types of users. And do a good job of overall planning and management to ensure the normal operation and post-maintenance and upgrade of the educational cloud platform.

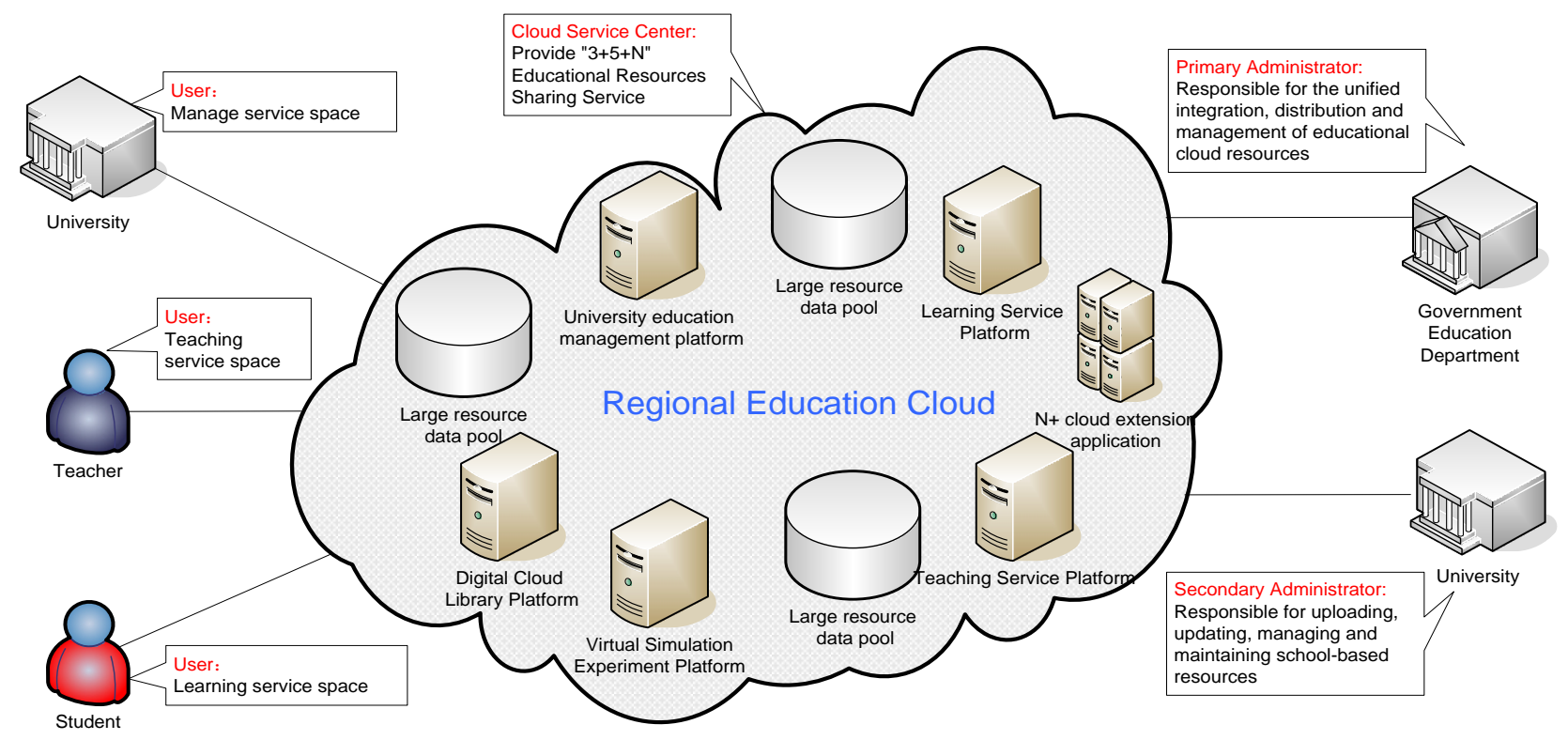

Figure 1. Regional Education Cloud System Framework Design.

At the management layer, the "primary administrator + secondary administrator" management system is mainly implemented to reflect the hierarchical management role and authority relationship. The government administrator belongs to the primary administrator and is responsible for the unified integration, distribution, and management of educational cloud resources, achieving the role management of the secondary manager, and having the highest operating authority of the educational cloud platform; the university administrators belong to the secondary manager., the primary responsibility for school-based resources is uploading, updating, maintaining, and managing.

At the user layer, the main members are universities, teachers and students. According to the different roles of users, the level of authority of the educational cloud platform given by the primary administrator is also different. Among them, university management personnel mainly request management services; teachers request teaching services; and students request learning services. 
Different roles, the open system interface and service functions of the educational cloud system are completely different, reflecting the principle of role-permission correspondence.

\section{Main functional module design of regional education cloud}

According to the system architecture of the designed regional education cloud platform, the system mainly includes the following functional modules:

University Education Management Module. The university education management module mainly provides intelligent educational management models for school-level management personnel. Its main functions include school management, personnel management, student management, educational administration management, financial management, school-based resource management, and school-school cooperative management, etc [8]. Through this module, it greatly simplifies the difficulty of education management and fully realizes the online education cloud management service. The major universities and colleges should make it easier for complicated education management, greatly improve office efficiency, save human resources, and achieve transparency in regional education management. In addition, schools can also use advanced education management information to learn and apply advanced experience, and promote the coordinated development of education management information in the region.

Teaching Service Module. In this function module, it is mainly for college teachers to provide the high-quality resources and services needed in the education and teaching process, disseminate advanced education concepts and teaching experience, and promote independent study and training for teachers. The high-quality teaching resources for the course mainly include curriculum PPT, teaching electronic lesson plans, teaching micro-teaching video, classic case analysis, and online courses. The services targeted at teachers' teaching and research are mainly online academic lectures, online teaching training classes, professional ability development training, teacher guidance, and project collaboration, which greatly mobilizes the enthusiasm of teachers for teaching and research, and helps teachers continuously improve their personal teaching ability. In addition, this functional module provides teachers with integrated application services for teaching and learning to help teachers complete the tedious preparation of teaching tasks more efficiently.

Learning Service Module. The learning service module is mainly oriented to the college student groups in the region, providing one-stop learning resources, online learning, professional assessment, teacher classrooms, interactive communication services. Students will be registered and certified safely through student number, ID number and real name, and build a harmonious and civilized inter-school, student-student, teacher-student interaction circle. Students can implement online self-study, share knowledge and experience in this module, and create a learner-centered interactive learning mode.

Virtual Simulation Lab Module. In major universities and colleges, there is a general lack of professional experimental platforms and equipment, which greatly reduces the practical effect of professional courses. In order to solve the shortage of experimental resources in colleges and universities, on the educational cloud platform, a virtual simulation laboratory module is designed to provide online cloud solutions for professional teaching in major universities. In this functional module, we will maximize the use of virtual reality technology and experimental resources, expand the limited physical experiment space into an unlimited virtual laboratory platform, and teachers and students can achieve professional experiment at any time, any space, any terminal equipment, to promote students' professional experiment level and ability.

Digital Cloud Library Module. In order to save investment in library construction funds in major universities, digital cloud library modules are integrated on the regional education cloud platform. This module integrates and integrates e-book resources of major universities and libraries in the region, realizes synchronized resource sharing, and provides online book services for users by using big data storage and cloud computing services. University users can download and browse cloud e-book resources through terminal devices[9].

$\mathrm{N}+$ expansion application module. The regional education cloud platform also provides $\mathrm{N}+$ expansion applications on the five basic services. The module mainly includes application services 
such as cloud classroom, intelligent group examination papers, quality question bank, cloud-aided design, cloud-assisted office, network competition, network selection, student comprehensive assessment, etc. And provide API interfaces for major universities to meet the customization needs of users. These expanded applications exist as an auxiliary means of education and teaching, provide users with more extended services, and are designed to promote the development of higher quality education and teaching activities[10].

\section{Conclusion}

This article mainly analyzes the current situation of the development of university resource sharing, puts forward the design principles and goals of the regional education cloud, and designs the basic framework and function modules of the regional education cloud based on the university's resource sharing, and provides a way for the development of regional education informatization. However, in the construction of an educational cloud platform, there will be many technical difficulties that need to be further studied and explored.

\section{References}

[1] P.Yu:Cloud Intelligence Education Exploration(Electronic Industry Press,China 2016).(In Chinese)

[2] G.L.Chen,Z.Ming:Cloud computing engineering(People Post Press,China 2016).(In Chinese)

[3] J.Zeng,W.L. Deng and N.N. Li:Research on the overall architecture of regional basic education cloud based on shared exchange cloud platform,J.Modern Computer,09(2014)26-27.(In Chinese).

[4] P.L.Wang:Cloud computing virtualization technology and application(People Post Press,China 2017).(In Chinese)

[5] W.T.Gong:Architecture Design of Regional Education Cloud Based on Resource Sharing,J.Microcomputer Applications,29(2013)41-42.(In Chinese)

[6] K.P.Ling,L.Wang:Cloud computing technology(People Post Press,China 2016).(In Chinese)

[7] S.L:Design and Implementation of Distributed Education Cloud Storage Platform(MS.,South China University of Technology, China 2016),p.20.

[8] M.Z.Zuo, S.S.Li and G.Deng:Construction of Regional Education Information Public Cloud Service Platform for Basic Education,J,Information Technology Education in Primary and Secondary Schools, 92-95.(In Chinese)

[9] F.Q.Luo,Y.Li and H.J.Chen:Big data technology foundation(People Post Press,China 2017).(In Chinese)

[10] J.Z.Hou:Research and Implementation of Smart Education Cloud Service Platform (MS.,Beijing industry university, China 2017),p.20. 